\title{
Silencing circ-BIRC6 inhibits the proliferation, invasion, migration and epithelial-mesenchymal transition of bladder cancer cells by targeting the miR-495-3p/XBP1 signaling axis
}

\author{
LEI ZHOU* , BINGZHI WANG* , YICHUAN ZHANG, KUN YAO and BIN LIU \\ Department of Urology, The Third Xiangya Hospital, Central South University, Changsha, Hunan 410013, P.R. China
}

Received January 14, 2021; Accepted June 14, 2021

DOI: $10.3892 / \mathrm{mmr} .2021 .12451$

\begin{abstract}
Circular RNAs (circRNAs) regulate gene expression by acting as a 'sponge' for microRNAs (miRs) and play crucial roles in tumorigenesis, including in bladder cancer (BC). circRNA-baculoviral IAP repeat-containing 6 (circ-BIRC6) has been reported to participate in the pathogenesis of several cancer types. The present study aimed to elucidate the roles and potential mechanisms of circ-BIRC6 in the progression of BC. circ-BIRC6 expression levels in $\mathrm{BC}$ cell lines were determined using reverse transcription-quantitative PCR. Following circ-BIRC6 knockdown, cell proliferation, invasion and migration were detected using Cell Counting Kit-8, colony formation, Transwell and wound healing assays, respectively. Western blotting was also conducted to evaluate the expression levels of X-box binding protein 1 (XBP1) and epithelial-mesenchymal transition (EMT)-associated proteins. In addition, rescue experiments were performed using by transfecting a miR-495-3p inhibitor into T24 cells following circ-BIRC6 knockdown. The interactions between circ-BIRC6, miR-495-3p and XBP1 was verified using dual luciferase reporter assays. Moreover, T24 cells with circ-BIRC6 knockdown and miR-495-3p inhibitor transfection were used for the tumor-bearing experiment. Tumor growth was observed and Ki-67 expression was determined using immunohistochemistry. The results demonstrated that circ-BIRC6 expression was upregulated in BC cell lines. Moreover, circ-BIRC6 knockdown notably attenuated the proliferation, invasion, migration and EMT of BC cells, which was blocked by the miR-495-3p inhibitor. It was also identified that circ-BIRC6 sponged miR-495-3p to regulate $\mathrm{XBP} 1$ expression. In addition, results from the xenograft
\end{abstract}

Correspondence to: Dr Bin Liu, Department of Urology, The Third Xiangya Hospital, Central South University, 138 Tongzipo Road, Yuelu, Changsha, Hunan 410013, P.R. China

E-mail: liubing32346@163.com

*Contributed equally

Key words: bladder cancer, circular RNA baculoviral IAP repeat-containing 6 , epithelial-mesenchymal transition experiments indicated that the knockdown of circ-BIRC6 and miR-495-3p expression significantly inhibited tumor growth. It was also found that the expression levels of XBP1, Ki-67 and EMT-associated proteins in tumor tissues of the co-transfection group were markedly restored compared with the circ-BIRC6 knockdown group. In conclusion, these findings demonstrated that circ-BIRC6 knockdown suppressed $\mathrm{BC}$ tumorigenesis and progression via regulation of the miR-495-3p/XBP1 signaling axis, offering a promising therapeutic target for the treatment of $\mathrm{BC}$.

\section{Introduction}

Bladder cancer (BC) is one of the most common malignancies in the genitourinary tract and has high morbidity and mortality rates (1). According to the statistics, $>400,000$ new cases of $\mathrm{BC}$ are diagnosed annually and $>2$ million patients currently suffer from this disease $(2,3)$. Despite therapeutic interventions, such as surgery, chemotherapy and radiotherapy, the 5-year survival rate of $\mathrm{BC}$ remains low, which is a significant economic burden (4-6). Thus, it is of great importance to identify novel biomarkers of $\mathrm{BC}$ and investigate the genetic regulatory networks involved in $\mathrm{BC}$ progression to improve patient prognosis and clinical outcomes.

Circular RNA (circRNA), a newly identified member of the non-coding RNA family, is characterized by a covalently closed loop without a 5'cap and 3'polyadenylated tail (7). Accumulating evidence has revealed that circRNAs exert key effects on multiple biological and pathological processes, such as proliferation, apoptosis, migration and metastasis, indicating that they may be involved in the occurrence and development of numerous types of disease, including cancer (8-10). circRNAs serve as competitive endogenous RNAs to modulate the activity of microRNAs (miRNAs/miRs) and restore miRNA-mediated suppression of target genes $(11,12)$. circRNA-baculoviral IAP repeat-containing 6 (circ-BIRC6) is generated by the back-splicing of the BIRC6 transcript (NM_016252) and has been reported to be associated with oncogenesis $(13,14)$. Previous studies have reported that BIRC6 expression was significantly upregulated in several human cancer types, such as hepatocellular carcinoma, prostate cancer and lung cancer (15-17). However, to the best of our knowledge, the role of circ-BIRC6 in BC remains to be elucidated and is therefore worthy of further investigations. 
The present study analyzed the expression levels of circ-BIRC6 in BC cell lines. Then, the effects of circ-BIRC6 on the biological functions of BC cells and on tumor growth were explored in vitro and in vivo. The potential underlying mechanisms of the effects of circ-BIRC6 in BC were also investigated. These results may offer novel insight into potential biomarkers for diagnosing and predicting the prognosis of patients with $\mathrm{BC}$.

\section{Materials and methods}

Cell lines and culture. Several BC cell lines (SW780, T24, J82 and 5637) and a human immortalized uroepithelium cell line (SV-HUC-1) were purchased from the American Type Culture Collection. SV-HUC-1, SW780 and T24 cells were cultured in DMEM (Gibco; Thermo Fisher Scientific, Inc.), while J82 and 5637 cells were cultured in RPMI-1640 medium (Gibco; Thermo Fisher Scientific, Inc.). All media were supplemented with 10\% FBS (Gibco; Thermo Fisher Scientific, Inc.). Cells were maintained in an incubator with $5 \% \mathrm{CO}_{2}$ at $37^{\circ} \mathrm{C}$.

Cell transfection. The pLVX lentiviral short hairpin RNA (shRNA/sh) circ-BIRC6 (sh-circ-BIRC6\#1 and sh-circ-BIRC6\#2) and sh-negative control (NC) vectors were synthesized by Shanghai GeneChem Co., Ltd. The miR-495-3p mimic (5'-AAACAAACATGGTGCACTTCT T-3'; 50 nM), miR-495-3p inhibitor (5'-GCTTTATATGTG ACGAAACAA-3'; $50 \mathrm{nM}$ ) and their controls [mimic NC (5'-ATCGTGCTAGTCGATGCTAGCT-3'; $50 \mathrm{nM}$ ) and NC inhibitor (5'-CGATCGCAGCGGTGCAGTGCG-3'; 50 nM)] were obtained from Shanghai GenePharma Co., Ltd. T24 cells $\left(2 \times 10^{5}\right.$ cells per well) were plated and incubated in 6-well plates for $24 \mathrm{~h}$. The transfection procedure was conducted at $37^{\circ} \mathrm{C}$ using Lipofectamine ${ }^{\circledR} 2000$ reagent (Invitrogen; Thermo Fisher Scientific, Inc.) according to the manufacturer's protocol. The transfection efficiency was evaluated using reverse transcription-quantitative PCR (RT-qPCR) following $48 \mathrm{~h}$ of transfection. The transfected cells were used for subsequent experiments at $48 \mathrm{~h}$ after transfection.

Cell proliferation assay. Briefly, $5 \times 10^{3}$ T24 cells/well were plated into 96 -well culture plates and cultured at $37^{\circ} \mathrm{C}$. Following 24, 48 or $72 \mathrm{~h}$ of incubation, $10 \mu \mathrm{l}$ Cell Counting Kit-8 (CCK-8) reagent (Shanghai Yeasen Biotechnology Co. Ltd.) was added into each well and the plates were cultured for a further $4 \mathrm{~h}$ at $37^{\circ} \mathrm{C}$. At $0 \mathrm{~h}, \mathrm{~T} 24$ cells would have just been seeded into a 96-well plate and would not reflect the activity of adherent cells. Therefore, the $0 \mathrm{~h}$ time point was omitted from the measurements. The optical density of each sample was determined at a wavelength of $450 \mathrm{~nm}$ using a microplate reader.

Colony formation assay. Following transfection, T24 cells were plated into 6 -well plates (500 cells/well). After incubation at $37^{\circ} \mathrm{C}$ for $7-10$ days, the cell colonies were washed with PBS, fixed with $4 \%$ paraformaldehyde for $10 \mathrm{~min}$ at room temperature and stained with $0.1 \%$ crystal violet for $15 \mathrm{~min}$ at room temperature. Images of the colonies were captured using a light microscope (Olympus Corporation; magnification, $\mathrm{x} 10)$.
Transwell assay. The invasive ability of T24 cells was determined using Transwell plates with $8-\mu \mathrm{m}$ pore inserts; the membranes were precoated with Matrigel (BD Biosciences) at $37^{\circ} \mathrm{C}$ for $6 \mathrm{~h}$. A total of $2 \times 10^{5}$ cells/well were resuspended in $200 \mu \mathrm{l}$ serum-free DMEM (Invitrogen; Thermo Fisher Scientific, Inc.) and plated into the upper chambers of the Transwell plates. The lower chambers were filled with $600 \mu \mathrm{l}$ DMEM supplemented with $10 \%$ FBS. After incubation for $24 \mathrm{~h}$ at $37^{\circ} \mathrm{C}$, the invasive cells were fixed with $4 \%$ paraformaldehyde $20 \mathrm{~min}$ at $37^{\circ} \mathrm{C}$ and stained with $0.1 \%$ crystal violet $10 \mathrm{~min}$ at $37^{\circ} \mathrm{C}$ for subsequent imaging and counting. Stained cells were visualized using an inverted light microscope (Olympus Corporation; magnification, x100).

Wound healing assay. For the wound healing assay, T24 cells were plated into 6 -well plates $\left(5 \times 10^{5}\right.$ cells/well) and cultured until they reached $90 \%$ confluence. Then, cells were incubated overnight in serum-free DMEM prior to initiating the experiment. The cell monolayer was subsequently scratched with a sterilized $100-\mu 1$ pipette tip. Following $24 \mathrm{~h}$ of incubation at $37^{\circ} \mathrm{C}$, the migration of cells was visualized using an inverted light microscope (Olympus Corporation; magnification, x100). Semi-quantitative analysis of the wound healing area was performed using ImageJ software (version 1.52r; National Institutes of Health).

Dual luciferase reporter assay. To study the mechanism via which circ-BIRC6 promotes BC progression, the potential miRNAs binding to circ-BIRC6 were predicted using the StarBase database (starbase.sysu.edu.cn). The wild-type (WT) and mutant (MUT) binding sites of miR-495-3p in the circ-BIRC6 or X-box binding protein 1 (XBP1) 3'-untranslated region (UTR) were sub-cloned into a pmirGLO dual luciferase reporter vector (Promega Corporation) to construct circ-BIRC6 WT/MUT and XBP1-WT/MUT vectors. Briefly, $5 \times 10^{3} \mathrm{~T} 24$ cells were seeded into 24 -well plates and cultured for $24 \mathrm{~h}$ at $37^{\circ} \mathrm{C}$. The plasmids were then co-transfected with miR-495-3p mimic or mimic NC into T24 cells using Lipofectamine ${ }^{\circledR} 2000$ (Invitrogen; Thermo Fisher Scientific, Inc.). Following $48 \mathrm{~h}$ of transfection, the relative luciferase activities were analyzed using a Dual Luciferase Reporter assay kit (Promega Corporation). Firefly luciferase activity was normalized to Renilla luciferase activity.

Immunofluorescence assay. Transfected cells were fixed with $4 \%$ paraformaldehyde at room temperature for $20 \mathrm{~min}$, followed by the addition of $0.05 \%$ Triton X-100 solution at room temperature for $10 \mathrm{~min}$. After blocking with $3 \% \mathrm{BSA}$ (Sigma-Aldrich; Merck KGaA) at $37^{\circ} \mathrm{C}$ for $90 \mathrm{~min}$, cells were incubated with a primary antibody against Ki-67 (cat. no. $11882 \mathrm{~S}$; 1:1,000; Cell Signaling Technology, Inc.) at $4^{\circ} \mathrm{C}$ overnight, followed by probing with the DyLight ${ }^{\mathrm{TM}}$ 488-conjugated secondary antibody (cat. no. ab96899; 1:250; Abcam) at $37^{\circ} \mathrm{C}$ for $1.5 \mathrm{~h}$ in the dark. The nuclei were stained with DAPI (Roche Diagnostics) in the dark for $5 \mathrm{~min}$ at room temperature. Images were captured under a fluorescence microscope (Olympus Corporation; magnification, x200) and the relative fluorescence intensity was used to quantify the Ki-67-postive cells in three randomly selected fields of view. The relative fluorescence intensity was normalized to the average optical density of the control group. 
In vivo xenograft experiments. A total of $12 \mathrm{BALB} / \mathrm{c}$ nude mice (age, 5-6 weeks; weight, $\sim 18-22 \mathrm{~g}$ ) were provided by the Shanghai Slac Animal Laboratory, and the animal experiments were approved by the Animal Care and Use Committee of The Third Xiangya Hospital, Central South University (Changsha, China). Mice were housed under pathogen-free conditions with a 12-h light/dark cycle, constant temperature of $25-27^{\circ} \mathrm{C}$ and constant humidity of $45-50 \%$. Mice had free access to food and water. Animals were randomly allocated into four groups (3 mice/group): sh-NC, sh-circ-BIRC6\#1,sh-circ-BIRC6\#1+NC inhibitor and sh-circ-BIRC6\#1+miR-495-3p inhibitor groups. T24 cells transfected with lentiviral sh-circ-BIRC6\#1, miR-495-3p or both were subcutaneously injected into the flank of nude mice $\left(5 \times 10^{6}\right.$ cells/mouse). Each mouse ( 7 weeks) was injected with $30 \mu \mathrm{l}$ cell suspension. Subsequently, the mice were maintained for 3 weeks. Tumor volume was recorded every 3 days. Tumor volume was calculated using the formula: Length $\mathrm{x}$ width ${ }^{2} / 2$. At the end of the experiments, all animals were sacrificed with an intraperitoneal injection of $100 \mathrm{mg} / \mathrm{kg}$ sodium pentobarbital (body weight). The tumor tissues were obtained for further investigation. The maximum tumor diameter and volume observed in the study were $19 \mathrm{~mm}$ and $1,519 \mathrm{~mm}^{3}$, respectively.

Immunohistochemistry analysis. Tumor tissues were fixed in $10 \%$ buffered formalin $24 \mathrm{~h}$ at room temperature and then embedded in paraffin. Paraffin-embedded tissue sections (4 $\mu \mathrm{m}$ thick) were deparaffinized with xylene and then rehydrated with a graded descending series of ethanol (100, 95 and $80 \%$ ). Following antigen retrieval in boiling water with a $10 \mathrm{mM}$ citrate buffer, endogenous hydrogen peroxidase activity was blocked by incubation with $10 \%$ hydrogen peroxide for $30 \mathrm{~min}$ at room temperature. The tissues samples were incubated with a primary rabbit anti-Ki-67 antibody (cat. no. 9027T; 1:500; Cell Signaling Technology, Inc.) at $4{ }^{\circ} \mathrm{C}$ overnight, then with an HRP-conjugated anti-rabbit IgG secondary antibody (cat. no. ab181658; 1:1,000; Abcam) for $2 \mathrm{~h}$ at room temperature. Subsequently, the tissue sections were treated with 3,3'-diaminobenzidine solution at room temperature for 3-5 min and counterstained with hematoxylin at room temperature for $5 \mathrm{~min}$. Sections were viewed under an inverted light microscope (Olympus Corporation; magnification, x100).

$R T$ - $q P C R$. Total RNA was extracted from cells or tumor tissues using TRIzol ${ }^{\circledR}$ reagent (Invitrogen; Thermo Fisher Scientific, Inc.), according to the manufacturer's protocol. Total RNA was reverse transcribed into cDNA using HiScript II (Vazyme Biotech Co., Ltd.) according to the manufacturer's protocol. qPCR to determine circ-BIRC6, miR-495-3p and XBP1 expression levels was subsequently performed using SYBR Select Master mix (Tiangen Biotech Co., Ltd.) on an ABI 7300 Real-Time PCR detection system (Applied Biosystems; Thermo Fisher Scientific, Inc.). The following thermocycling conditions were used: Initial denaturation at $95^{\circ} \mathrm{C}$ for $10 \mathrm{~min}$; followed by 40 cycles of denaturation at $95^{\circ} \mathrm{C}$ for $15 \mathrm{sec}$ and annealing at $60^{\circ} \mathrm{C}$ for $1 \mathrm{~min}$; and a final extension of $10 \mathrm{~min}$ at $72^{\circ} \mathrm{C}$. The primers used were: circ-BIRC6 forward, 5'-TGA AAGGTTCTTGCACGCAT-3' and reverse, 5'-GCTGGG GTTCGTTCACAATC-3'; miR-495-3p forward, 5'-AAACAA ACAUGGUGCACUUCUU-3' and reverse, 5'-GAAGUGCAC
CAUGUUUGUUUUU-3'; XBP1s forward, 5'-ATGGATGCC CTGGTTGCTGAAGA-3' and reverse, 5'-TGCACCTGCTGC GGACTCA-3'; XBP1u forward, 5'-AGCACTCAGACTACG TGCACCTCT-3' and reverse, 5'-CCAGAATGCCCAACA GGATATCAG-3'; U6 forward, 5'-CTCGCTTCGGCAGCA CA-3' and reverse, 5'-AACGCTTCACGAATTTGCGT-3'; GAPDH forward, 5'-ACAACTTTGGTATCGTGGAAGG-3' and reverse, 5'-GCCATCACGCCACAGTTTC-3'. U6 levels were used to normalize miR-495-3p expression. GAPDH the was endogenous control for circ-BIRC6. The relative expression levels were quantitatively analyzed using the $2^{-\Delta \Delta \mathrm{Cq}}$ method (18).

Western blotting. Total protein was extracted from cells or tumor tissues using RIPA lysis buffer (Beyotime Institute of Biotechnology). Protein concentration was quantified using a BCA assay kit (Beyotime Institute of Biotechnology) and equal amounts of protein (40 $\mu \mathrm{g}$ protein/lane) were separated via 10\% SDS-PAGE. The proteins were subsequently transferred onto PVDF membranes (Thermo Fisher Scientific, Inc.) and blocked with $5 \%$ skimmed milk at room temperature for $2 \mathrm{~h}$. The membranes were then incubated with specific primary antibodies at $4^{\circ} \mathrm{C}$ overnight. The following primary antibodies were used: anti-E-cadherin (cat. no. 3195T; 1:1,000; Cell Signaling Technology, Inc.), anti-N-cadherin (cat. no. 13116T; 1:1,000; Cell Signaling Technology, Inc.), anti-Vimentin (cat. no. 5741T; 1:1,000; Cell Signaling Technology, Inc.), anti-Snail (cat. no. 3879T; 1:1,000; Cell Signaling Technology, Inc.), anti-XBP1s/u (cat. no. bs-1668R; 1:1,000; Bioss) and anti-GAPDH (cat. no. 5174T; 1:1,000; Cell Signaling Technology, Inc.). Following the primary antibody incubation, the membranes were incubated with an HRP-conjugated secondary antibody for $1.5 \mathrm{~h}$ at room temperature. Protein bands were visualized using an ECL reagent (MilliporeSigma) and the bands were semi-quantified using ImageJ software (version 1.52r; National Institutes of Health). The gray value of the target protein was normalized to that of GAPDH.

Statistical analysis. Data are presented as the mean \pm SD and statistical analysis was performed using GraphPad Prism 8.0 software (GraphPad Software, Inc.). All experiments were repeated independently in triplicate. One way ANOVA followed by a Tukey's post hoc test was used to analyze the significant differences among multiple groups. $\mathrm{P}<0.05$ was considered to indicate a statistically significant difference.

\section{Results}

circ-BIRC6 expression levels are upregulated in BC cell lines and circ-BIRC6 knockdown inhibits the proliferation of $B C$ cells. Firstly, the expression levels of circ-BIRC6 in several BC cell lines (SW780, T24, J82 and 5637) and a human immortalized uroepithelium cell line (SV-HUC-1) were detected using RT-qPCR. As presented in Fig. 1A, circ-BIRC6 expression was found to be upregulated in BC cell lines compared with the SV-HUC-1 cells, especially in the T24 cells, which were used for the subsequent experiments. Next, circ-BIRC6 was silenced in T24 cells via transfection with sh-circ-BIRC6\#1 or sh-circ-BIRC6\#2. The results revealed that BIRC6 expression was significantly downregulated in the sh-circ-BIRC6 groups 

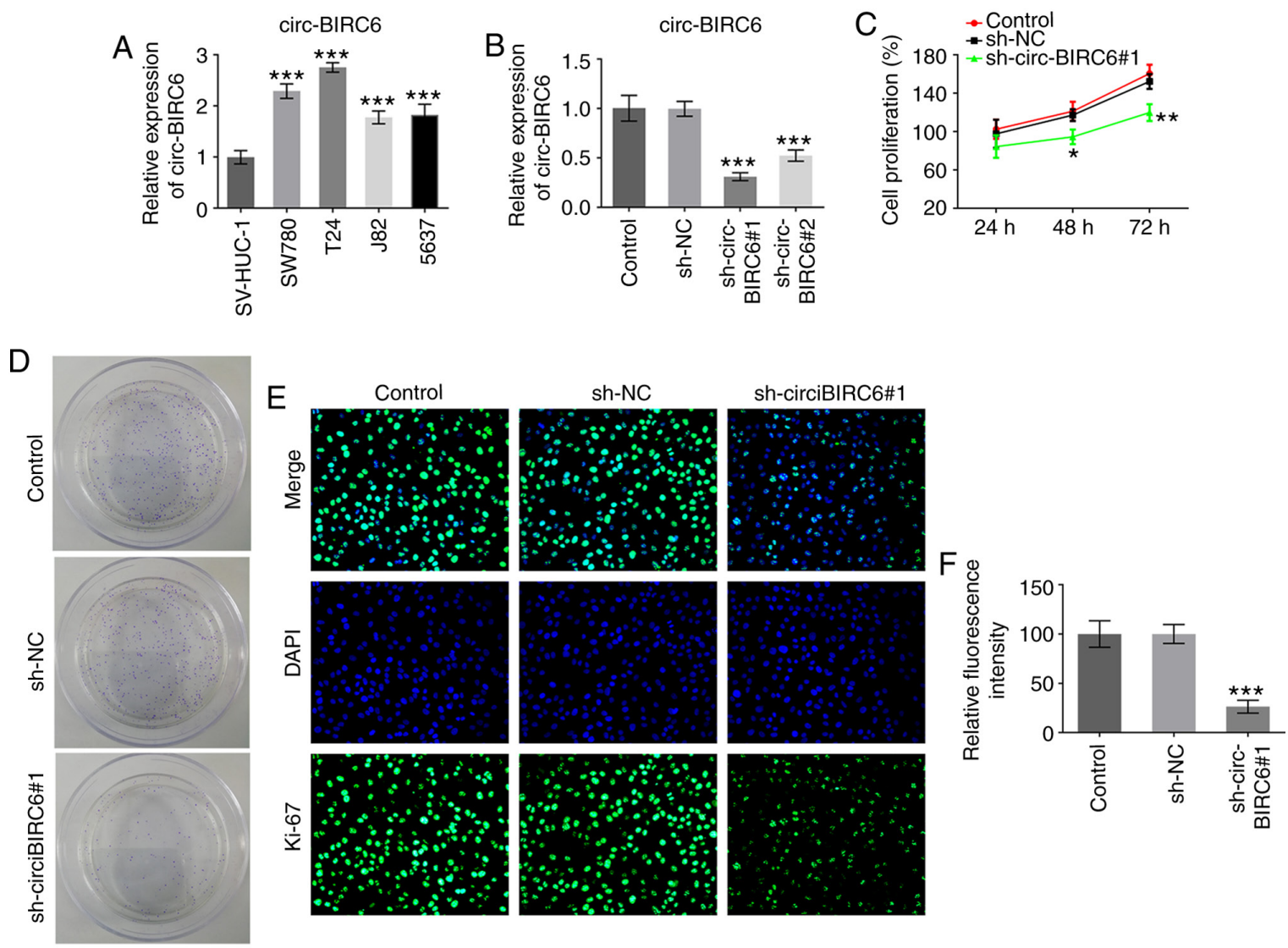

Figure 1. circ-BIRC6 is highly expressed in BC cell lines and circ-BIRC6 knockdown inhibits the proliferation of BC cells. (A) BIRC6 expression was detected using RT-qPCR in several BC cell lines (SW780, T24, J82 and 5637) and a human immortalized uroepithelium cell line (SV-HUC-1). ${ }^{* * *} \mathrm{P}<0.001$ vs. SV-HUC-1. (B) BIRC6 expression in T24 cells was measured using RT-qPCR after transfection. (C) Cell proliferation was determined using a Cell Counting Kit-8 kit. (D) Colony formation assay of T24 cells. (E) Ki-67 expression was assessed using immunofluorescence. (F) Fluorescence intensity from part (E). Magnification, $\mathrm{x} 200 .{ }^{*} \mathrm{P}<0.05,{ }^{* *} \mathrm{P}<0.01,{ }^{* * *} \mathrm{P}<0.001$ vs. sh-NC. NC, negative control; sh, short hairpin RNA; RT-qPCR, reverse transcription-quantitative PCR; circ-BIRC6, circular RNA baculoviral IAP repeat-containing 6; BC, bladder cancer.

compared with the sh-NC group, and T24 cells transfected with sh-circ-BIRC6\#1 decreased the expression of circ-BIRC6 to a greater extent than sh-circ-BIRC6\#2 (Fig. 1B). Therefore, sh-circ-BIRC6\#1 was selected for use in further experiments. The results demonstrated that cell proliferation was markedly reduced following circ-BIRC6 knockdown compared with the sh-NC group (Fig. 1C). Moreover, the colony formation assay results revealed that the proliferative ability of T24 cells was markedly suppressed in the sh-circ-BIRC6\#1 group compared with the sh-NC group (Fig. 1D). Simultaneously, the expression levels of the proliferation-related protein, Ki-67, were significantly decreased following circ-BIRC6 knockdown compared with the sh-NC group (Fig. 1E). These findings suggested that circ-BIRC6 may be upregulated in BC cells and that circ-BIRC6 knockdown may decrease the proliferation of $\mathrm{BC}$ cells.

circ-BIRC6 knockdown prevents the invasion, migration and epithelial-mesenchymal transition (EMT) of BC cells. Subsequently, the effects of BIRC6 knockdown on cell invasion were measured using a Transwell assay. As shown in Fig. 2A and B, the invasive ability of T24 cells was significantly inhibited in the sh-circ-BIRC6\#1 group compared with the sh-NC group. Consistently, the results from the wound healing assay showed the same trend with cell migration (Fig. 2C and D). In addition, the expression levels of EMT-related proteins were analyzed using western blotting. The expression levels of E-cadherin were significantly upregulated in the sh-circ-BIRC6\#1 group compared with the sh-NC group, while the expression levels of $\mathrm{N}$-cadherin, vimentin and snail family transcriptional repressor 1 (snail) were downregulated in T24 cells following circ-BIRC6 knockdown (Fig. 2E). These results indicated that circ-BIRC6 knockdown may block the invasion, migration and EMT of $\mathrm{BC}$ cells.

circ-BIRC6 acts as a sponge for miR-495-3p. To study the mechanism via which circ-BIRC6 promotes BC progression, the potential miRNAs binding to circ-BIRC6 were predicted using the StarBase database (http://starbase.sysu.edu.cn), which identified miR-495-3p as a candidate molecule. A putative binding site between circ-BIRC6 and miR-495-3p was identified and is presented in Fig. 3A. The expression levels of miR-495-3p were significantly downregulated in BC cells compared with SV-HUC-1 cells (Fig. 3B). After successful transfection of T24 cells with the miR-495-3p mimic (Fig. 3C), the relative luciferase activity of the circ-BIRC6 WT vector was reduced compared with the mimic NC group (Fig. 3C and D). Moreover, circ-BIRC6 knockdown significantly upregulated the expression levels of miR-495-3p in T24 cells compared 
A

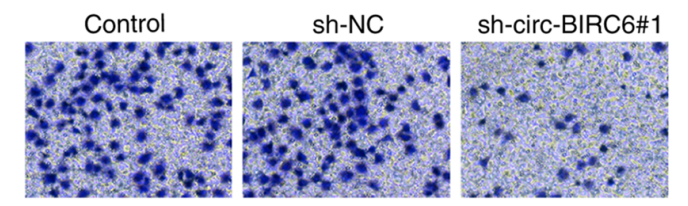

C
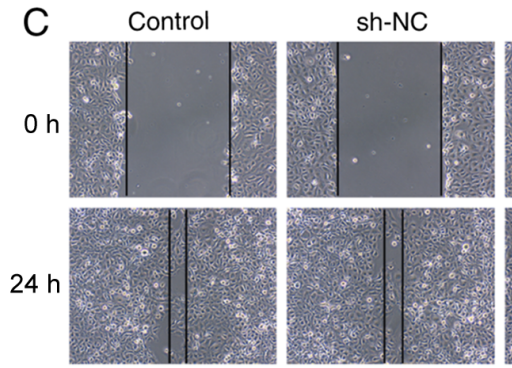

sh-circ-BIRC6\#1

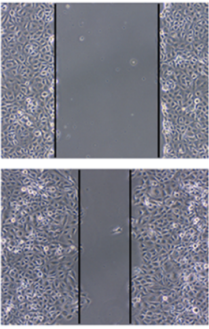

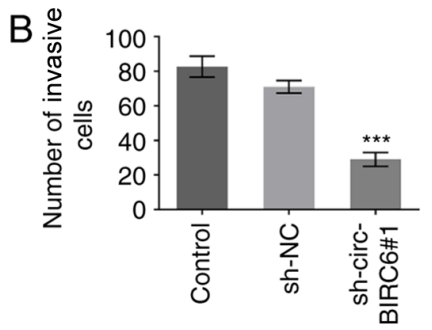

$\mathrm{D}$

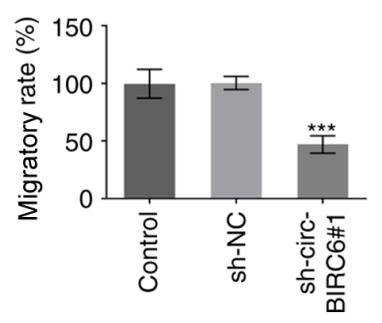

$\mathrm{E}$

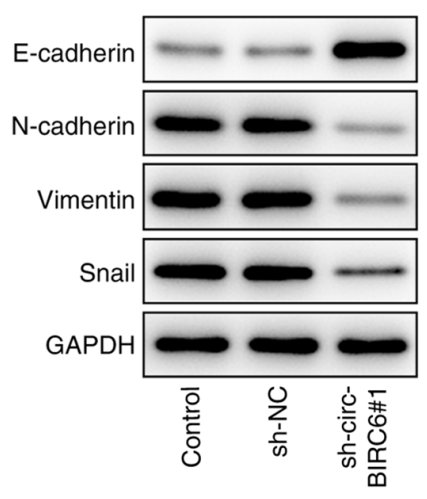

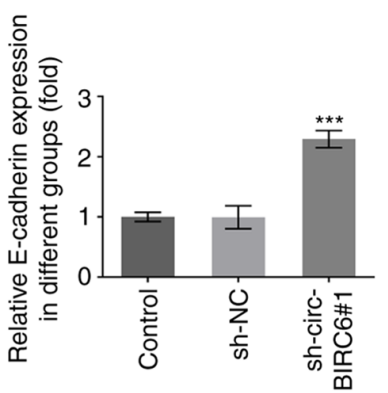
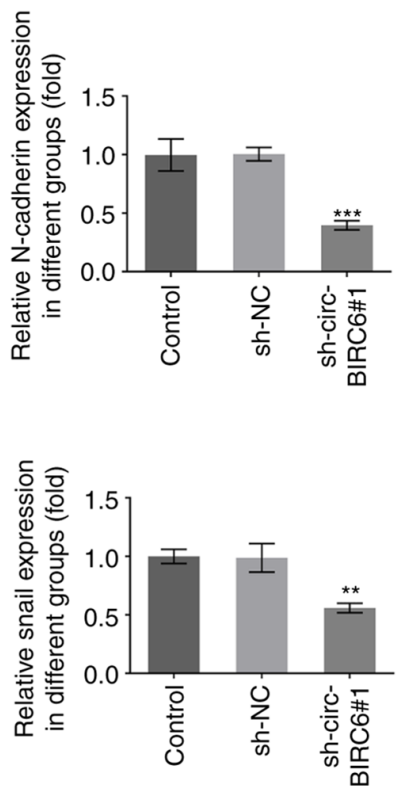

Figure 2. circ-BIRC6 silencing suppresses the invasion, migration and EMT of bladder cancer cells. (A and B) Transwell assay was used to evaluate the effects of BIRC6 silencing on the invasion of T24 cells. Magnification, x100. (C and D) Cell migration was evaluated using a wound healing assay. (E) Expression levels of EMT-associated proteins, including E-cadherin, $\mathrm{N}$-cadherin, vimentin and snail, were determined using western blotting. ${ }^{* *} \mathrm{P}<0.01$, ${ }^{* * *} \mathrm{P}<0.001$ vs. sh-NC. NC, negative control; sh, short hairpin RNA; circ-BIRC6, circular RNA baculoviral IAP repeat-containing 6; EMT, epithelial-mesenchymal transition; snail, snail family transcriptional repressor 1.

with the sh-NC group (Fig. 3E), further suggesting that circ-BIRC6 may act as a sponge for miR-495-3p.

miR-495-3p inhibitor rescues the effects induced by circ-BIRC6 knockdown in BC cells. To further elucidate the regulatory association between circ-BIRC6 and miR-495-3p in $\mathrm{BC}$, the mRNA expression levels of miR-495-3p were successfully silenced via transfection with a miR-495-3p inhibitor (Fig. 4A). Co-transfection with miR-495-3p inhibitor and sh-circ-BIRC6\#1 enhanced the proliferative ability of T24 cells compared with those in cells transfected with sh-circ-BIRC6\#1 alone, which was accompanied by an increase in Ki-67 expression (Fig. 4B-E). Additionally, the invasive and migratory abilities of cells were significantly elevated following miR-495-3p silencing in T24 cells with sh-circ-BIRC6\#1 transfection compared with the sh-circ-BIRC6\#1+NC inhibitor group (Fig. 5A-D). Moreover, co-transfection with the miR-495-3p inhibitor and sh-circ-BIRC6\#1 markedly downregulated the expression levels of E-cadherin and upregulated those of $\mathrm{N}$-cadherin, vimentin and snail in T24 cells compared with cells transfected with sh-circ-BIRC6\#1 alone (Fig. 5E). These findings provide evidence to suggest that circ-BIRC6 may regulate the progression of BC cells by targeting miR-495-3p.

circ-BIRC6 regulates the expression levels of XBP1 via modulating $m i R-495-3 p$. The bioinformatics results identified that XBP1 was a potential target gene of miR-495-3p, which was confirmed using a dual luciferase reporter assay (Fig. 6A and B). Furthermore, compared with SV-HUC-1 cells, the mRNA and protein expression levels of XBP1s/u were upregulated in $\mathrm{BC}$ cell lines when compared with SV-HUC-1 cells (Fig. 6C and D). Notably, T24 cells transfected with sh-circ-BIRC6\#1 exhibited a decreased expression level of XBP1s/u compared with the 


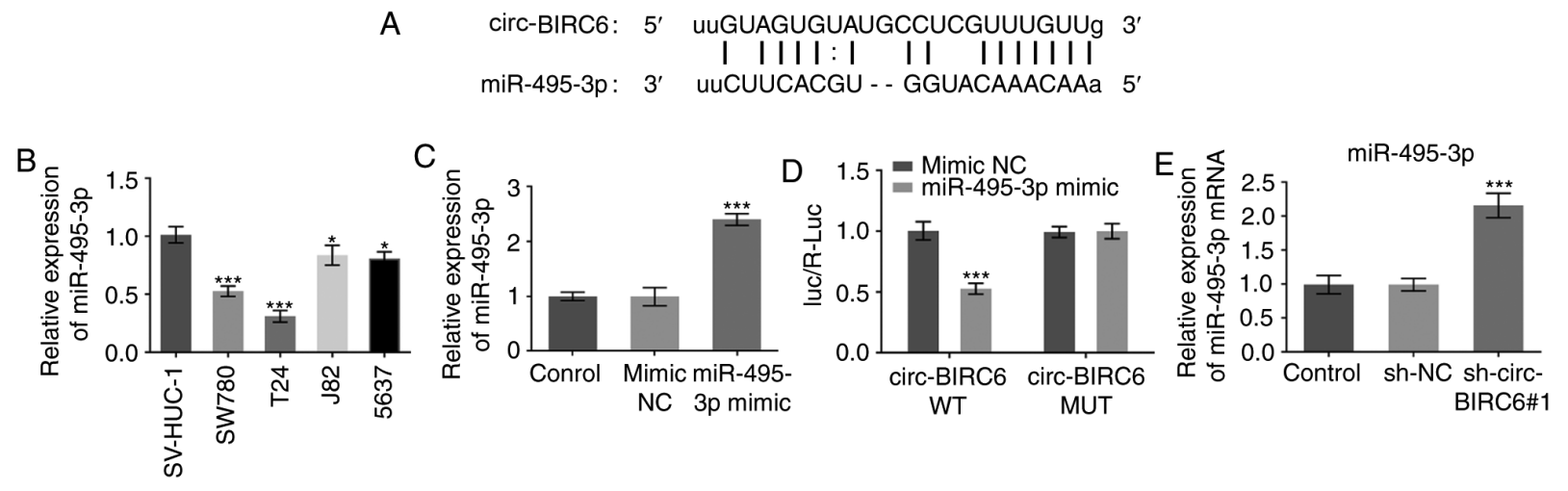

Figure 3. circ-BIRC6 acts as a sponge for miR-495-3p. (A) Binding region between circ-BIRC6 and miR-495-3p is shown. (B) Expression levels of miR-495-3p in several BC cell lines were determined using RT-qPCR. "P<0.05, ${ }^{* * * *} \mathrm{P}<0.001$ vs. SV-HUC-1. (C) RT-qPCR was employed to detect the expression levels of miR-495-3p in T24 cells. ${ }^{* * * *} \mathrm{P}<0.001$ vs. mimic NC. (D) Relative luciferase activities were detected in T24 cells. ${ }^{* * * *} \mathrm{P}<0.001 \mathrm{vs}$. circ-BIRC6 WT + mimic NC. (E) miR-495-3p expression was assessed using RT-qPCR in T24 cells following circ-BIRC6 silencing. ${ }^{* * *} \mathrm{P}<0.001$ vs. sh-NC. NC, negative control; sh, short hairpin RNA; circ-BIRC6, circular RNA baculoviral IAP repeat-containing 6; miR, microRNA; RT-qPCR, reverse transcription-quantitative PCR; Luc, luciferase; R, Renilla; WT, wild-type; MUT, mutant.
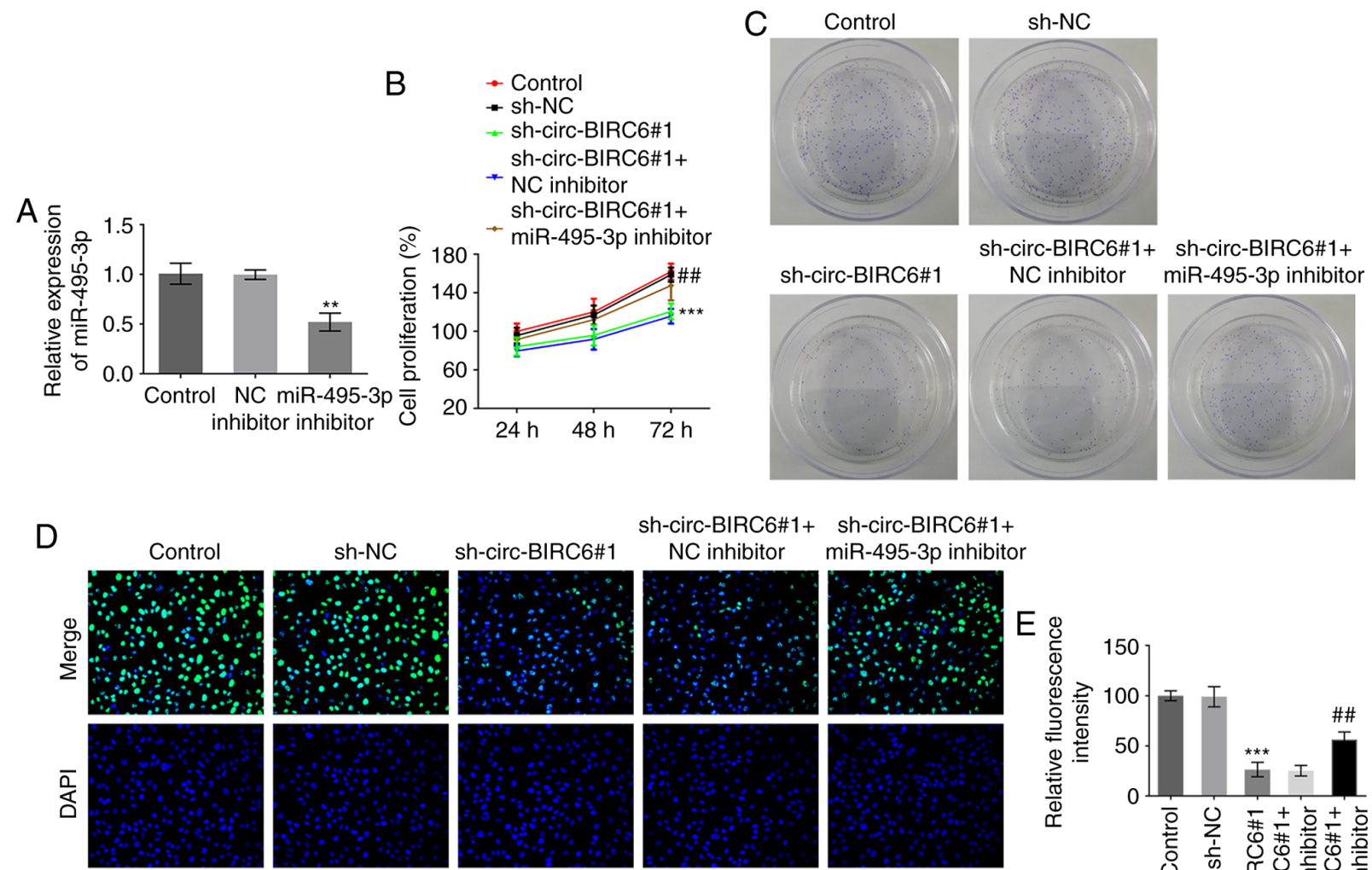

sh-circ-BIRC6\#1+ sh-circ-BIRC6\#1+
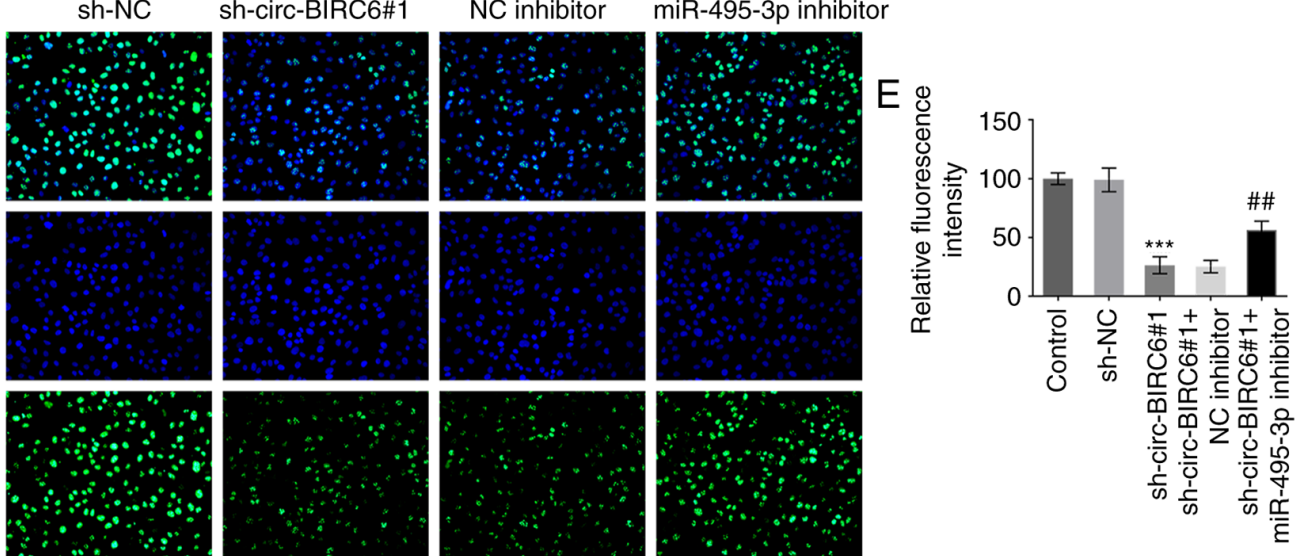

Figure 4. miR-495-3p inhibitor restores the effects of circ-BIRC6 knockdown on the proliferation of bladder cancer cells. (A) miR-495-3p expression was evaluated using reverse transcription-quantitative PCR after transfection with the miR-495-3p inhibitor. ${ }^{* * *} \mathrm{P}<0.01$ vs. NC inhibitor. (B) Cell proliferation was assessed using a Cell Counting Kit-8 assay. (C) Colony formation assay. ${ }^{* * *} \mathrm{P}<0.001$ vs. sh-NC; ${ }^{\# \#} \mathrm{P}<0.01$ vs. sh-circ-BIRC6\#1 + NC inhibitor. (D) Ki-67 expression was assessed using immunofluorescence. Magnification, $x 200$. (E) Fluorescence intensity from part (D). ${ }^{* * *} \mathrm{P}<0.001 \mathrm{vs}$. sh-NC; ${ }^{\# \#} \mathrm{P}<0.01 \mathrm{vs}$. sh-circ-BIRC6\#1 + NC inhibitor. NC, negative control; sh, short hairpin RNA; circ-BIRC6, circular RNA baculoviral IAP repeat-containing 6; miR, microRNA.

sh-NC group, which was blocked by the miR-495-3p inhibitor (Fig. 6E and F). Taken together, these data provide evidence to indicate that circ-BIRC6 may regulate the expression level of XBP1 via modulating miR-495-3p.
circ-BIRC6 silencing suppresses the growth of BC xenografts by regulating the $m i R-495-3 p / X B P 1$ signaling axis. Next, to analyze the role of circ-BIRC6 in BC, a BALB/c nude mice model was established. The xenograft results demonstrated 

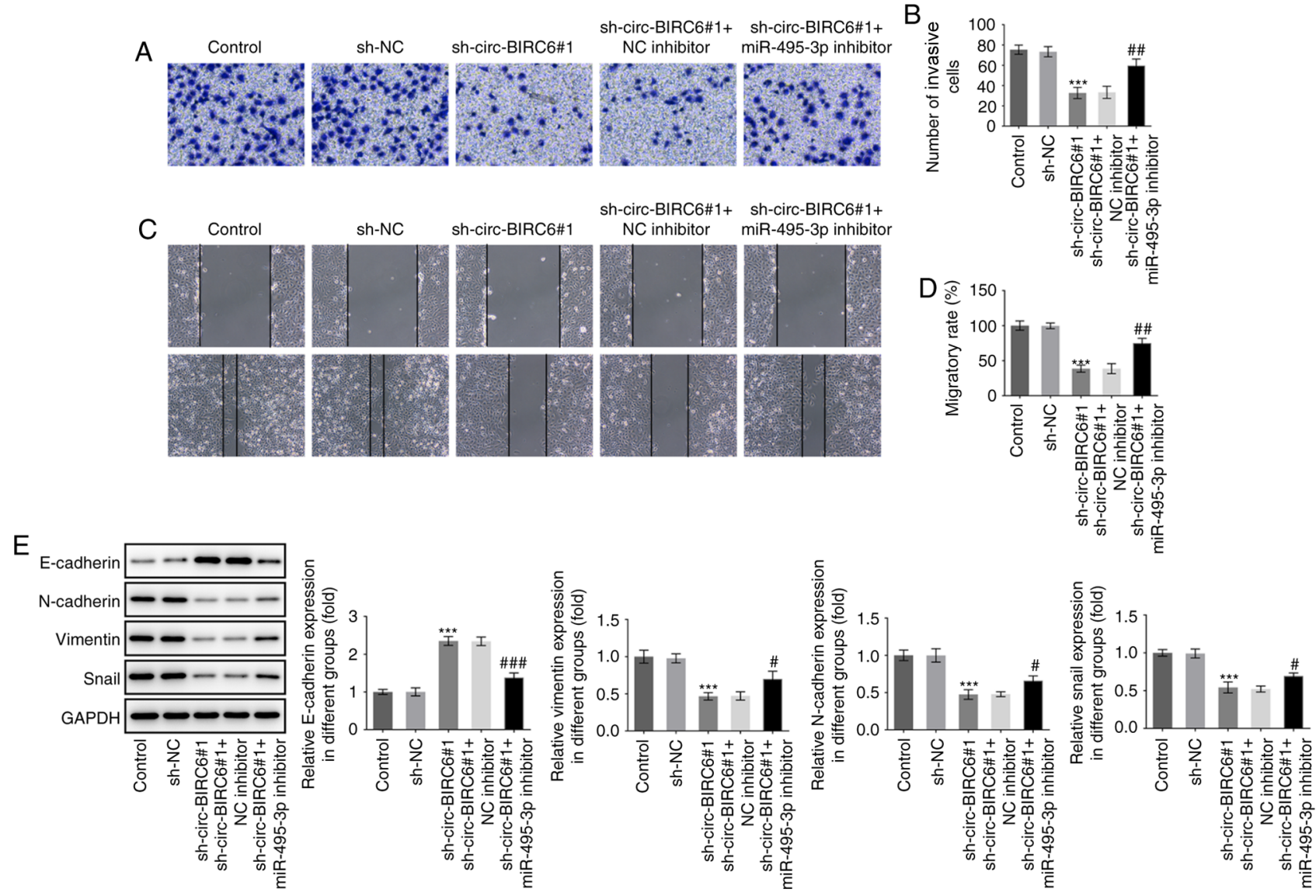

Figure 5. miR-495-3p inhibitor attenuates the effects of circ-BIRC6 knockdown on the invasion, migration and EMT of bladder cancer cells. T24 cell (A and B) invasion and (C and D) migration were detected using Transwell and wound healing assays, respectively. Magnification, x100. (E) Western blotting was used to determine the expression levels of EMT-related proteins, including E-cadherin, N-cadherin, vimentin and snail. ${ }^{* * *} \mathrm{P}<0.001 \mathrm{vs}$. sh-NC;

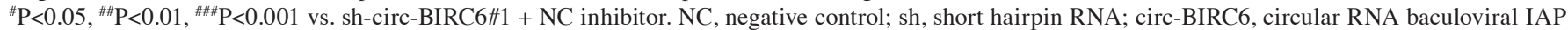
repeat-containing 6; miR, microRNA; EMT, epithelial-mesenchymal transition. snail, snail family transcriptional repressor 1.

that circ-BIRC6 knockdown notably inhibited tumor weight and volume compared with the sh-NC group (Fig. 7A-D). By contrast, the miR-495-3p inhibitor partially counteracted the inhibitory effects of circ-BIRC6 knockdown on the growth of tumors. Additionally, notably downregulated XBP1s/u expression was observed in tumor tissues of xenograft mice in the sh-circ-BIRC6\#1 group compared with the sh-NC group, while miR-495-3p knockdown markedly reversed their expression levels (Fig. 7E and F). Moreover, immunohistochemical detection of Ki-67 staining demonstrated that silencing of circ-BIRC6 inhibited $\mathrm{Ki}-67$ expression in tumor tissues compared with the sh-NC group (Fig. 7G). It was also found that the tumor tissues that were transplanted with T24 cells (silenced for circ-BIRC6 and miR-495-3p expression) exhibited an elevated expression of $\mathrm{Ki}-67$ when compared with sh-circ-BIRC6\#1+NC inhibitor group. Moreover, it was identified that circ-BIRC6 knockdown notably upregulated the expression levels of E-cadherin, but downregulated those of $\mathrm{N}$-cadherin, vimentin and snail compared with the sh-NC group (Fig. 7H). The results also indicated that the miR-495-3p inhibitor partially abrogated the effect of circ-BIRC6 silencing on the expression levels of the aforementioned proteins. These data suggested that circ-BIRC6 knockdown may suppress the growth of $\mathrm{BC}$ cancer xenografts by regulating the miR-495-3p/XBP1 signaling axis.

\section{Discussion}

Previous studies have reported that circRNAs participate in the occurrence and progression of numerous cancer types, such as glioma, gastric and bladder cancer, by acting as sponges of miRNAs and keeping target genes away from miRNAs (19-21). There is an urgent requirement to increase the current understanding of the molecular mechanisms underlying $\mathrm{BC}$ development. In the present study, it was first demonstrated that circ-BIRC6 expression was upregulated in BC cell lines. Functional experiments identified that circ-BIRC6 silencing suppressed the progression of BC by mediating the behaviors of cancer cells (proliferation, invasion, migration and EMT). In addition, the results of the mechanistic studies revealed that circ-BIRC6 acted as a competing endogenous RNA (ceRNA) for miR-495-3p to promote XBP1 expression. The present findings highlighted the vital roles of the circ-BIRC6/miR-495-3p/XBP1 signaling axis in the progression of $\mathrm{BC}$.

Accumulating evidence has shown that abnormal proliferation is recognized as a feature of BC cells (22-24). Moreover, invasion and metastasis are the most challenging obstacles to successful tumor treatment and are the leading cause for the resultant mortality of patients with BC $(25,26)$. EMT, a crucial driver of tumor progression, is characterized by loss 


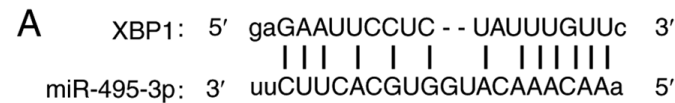

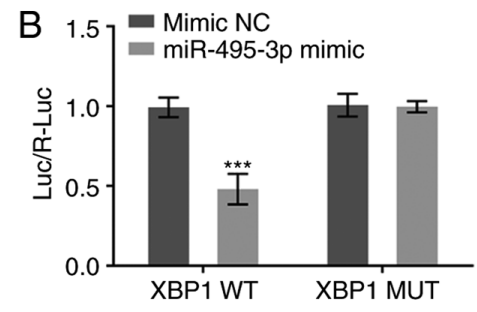

$\mathrm{D}$

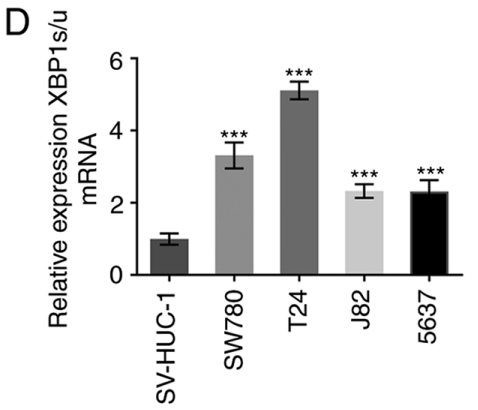

$\mathrm{E}$
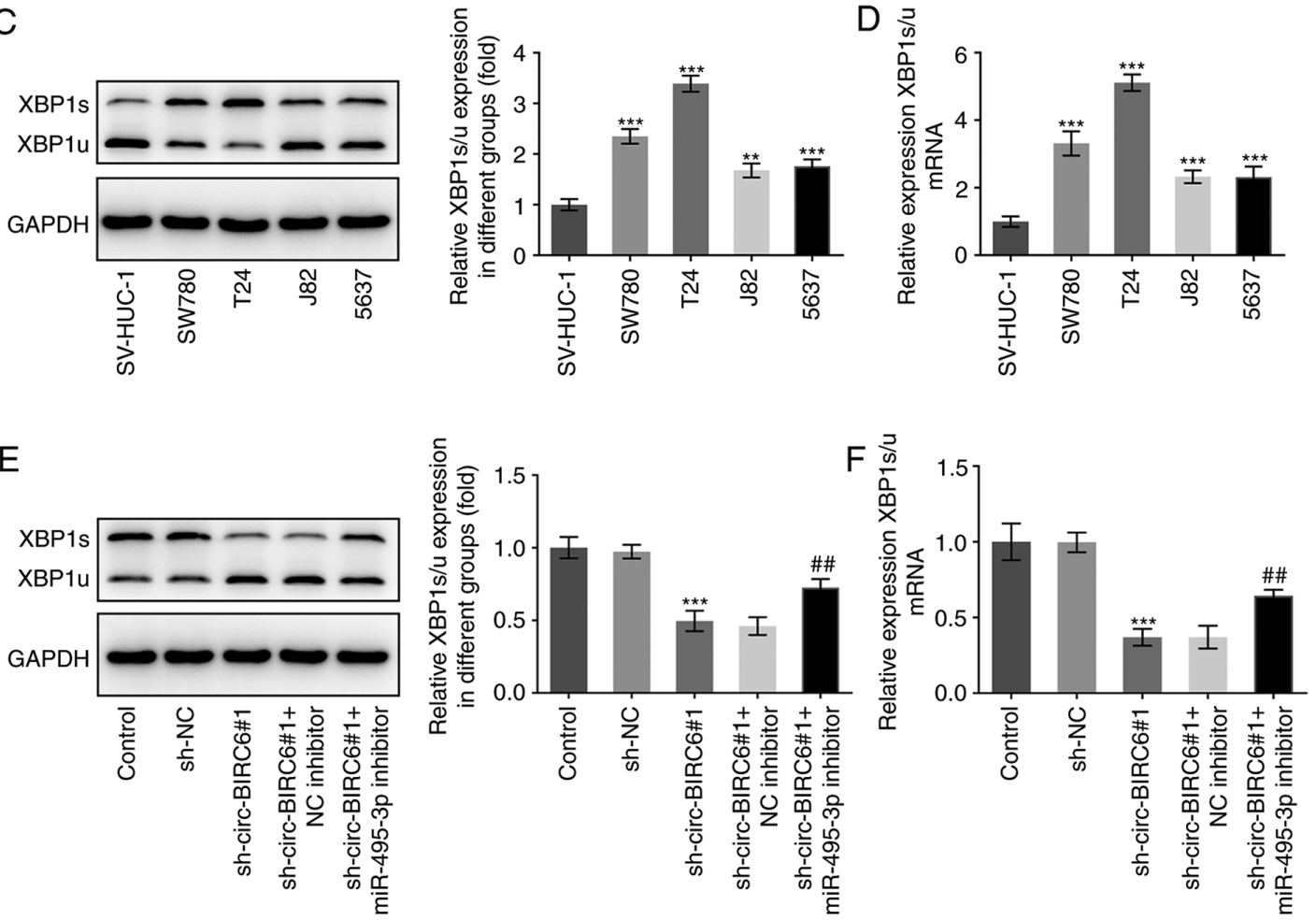

Figure 6. circ-BIRC6 regulates the expression of XBP1 via miR-495-3p. (A) Binding region between XBP1 and miR-495-3p is shown. (B) Relative luciferase activities were detected in T24 cells. ${ }^{* * *} \mathrm{P}<0.001$ vs. XBP1 WT+ mimic NC. Protein and mRNA expression levels of XBP1 were examined using $(\mathrm{C})$ western blotting and (D) RT-qPCR, respectively. ${ }^{* *} \mathrm{P}<0.01,{ }^{* * *} \mathrm{P}<0.001 \mathrm{SV}-\mathrm{HUC}-1$. (E) Western blotting and (F) RT-qPCR were employed to measure the protein and mRNA expression levels, respectively, of XBP1 after co-transfection with sh-circ-BIRC6\#1 and miR-495-3p inhibitor. ${ }^{* * *} \mathrm{P}<0.001 \mathrm{vs}$. sh-NC; ${ }^{\# \#} \mathrm{P}<0.01$ vs. sh-circ-BIRC6\#1 + NC inhibitor. NC, negative control; sh, short hairpin RNA; circ-BIRC6, circular RNA baculoviral IAP repeat-containing 6; miR, microRNA; XBP1, X-box binding protein 1; WT, wild-type; MUT, mutant; Luc, luciferase; R, Renilla; RT-qPCR, reverse transcription-quantitative PCR.

of cell-cell adhesion and cell polarity that increases cell invasion and migration (27). The EMT process is accompanied by the downregulation of epithelial markers (E-cadherin) and upregulation of mesenchymal markers (N-cadherin, vimentin and snail) $(28,29)$. In this regard, interruption of the aforementioned processes is an effective method to inhibit cancer development. In the present study, circ-BIRC6 knockdown upregulated E-cadherin expression and downregulated $\mathrm{N}$-cadherin, Vimentin and Snail expression.

circRNAs have been found to participate in tumorigenesis by regulating multiple biological processes, such as growth, migration and invasion (30-32). circ-BIRC6 was reported to accelerate the progression of non-small cell lung cancer by potently promoting the proliferation, invasion and migration of cancer cells (33). In addition, it was revealed that circ-BIRC6 knockdown suppressed hepatocellular carcinoma cell proliferation, invasion and migration (13). However, to date, there is no previous literature regarding the expression and/or role of circ-BIRC6 in BC tissues and/or animal and cell models. The results of the present study identified that circ-BIRC6 was upregulated in BC cell lines, and silencing of circ-BIRC6 notably suppressed the proliferation, invasion, migration and EMT process of BC cells, suggesting the inhibitory effects of circ-BIRC6 on the progression of BC.

circRNAs can function as ceRNAs to regulate biological activity by sponging miRNAs to completely or partially relieve their suppression of target mRNAs (34). With regards to their underlying mechanism, the current study bioinformatics analysis predicted that miR-495-3p was a potential target miRNA of circ-BIRC6, which was verified using a dual luciferase reporter assay. According to previous studies, miR-495-3p exerted a tumor suppressive effect in several cancer types. For instance, miR-495-3p expression was found to be downregulated in colorectal cancer (35). Moreover, miR-495-3p restrained the proliferation, invasion and migration of osteosarcoma cells by directly targeting complement C1q/TNF-related protein 3 (36). It is also worth noting that miR-495-3p expression was reported to be downregulated in glioma tissues and cells, and that miR-495-3p overexpression markedly inhibited the proliferation, invasion and EMT of glioma cells (37). In the present study, 


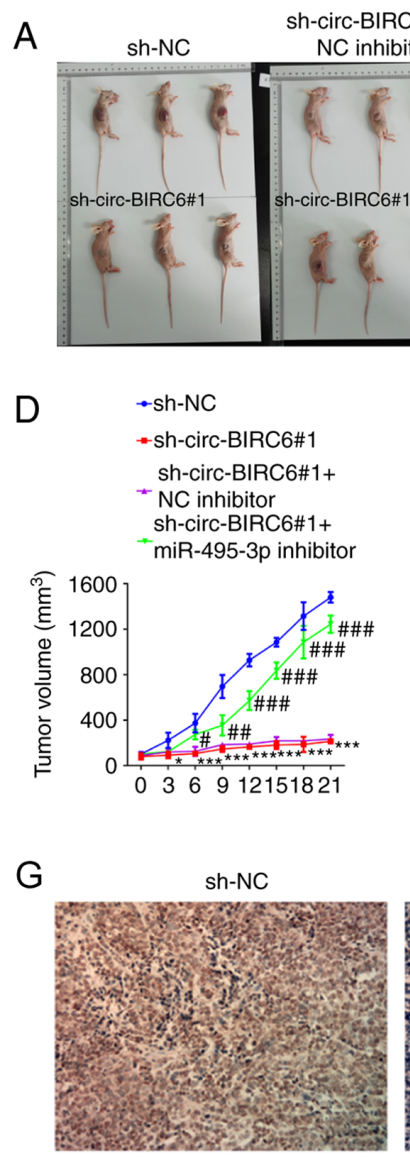

$\mathrm{H}$
$\mathrm{E}$

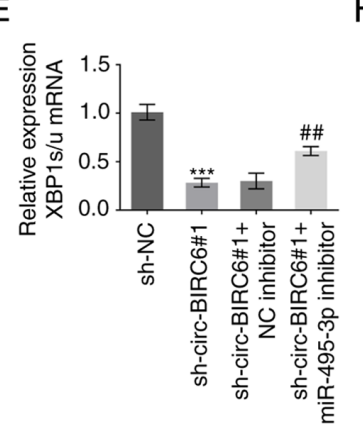

B

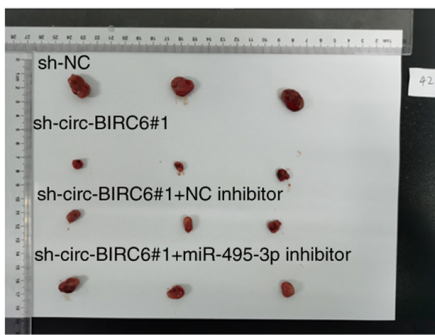

F

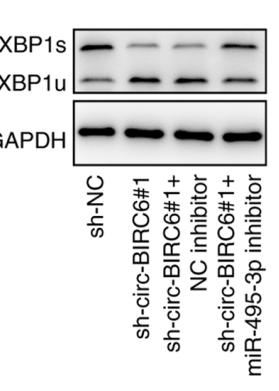

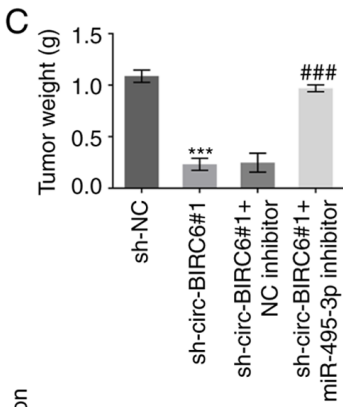

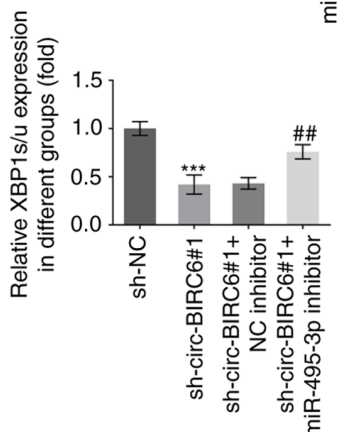

sh-circ-BIRC6\#1+ miR-495-3p inhibitor

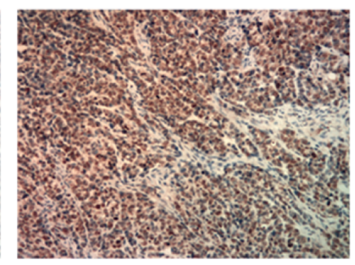

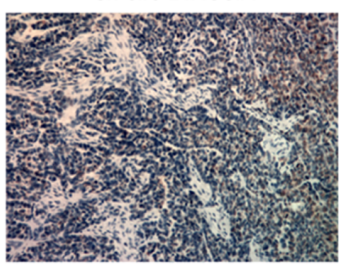

동
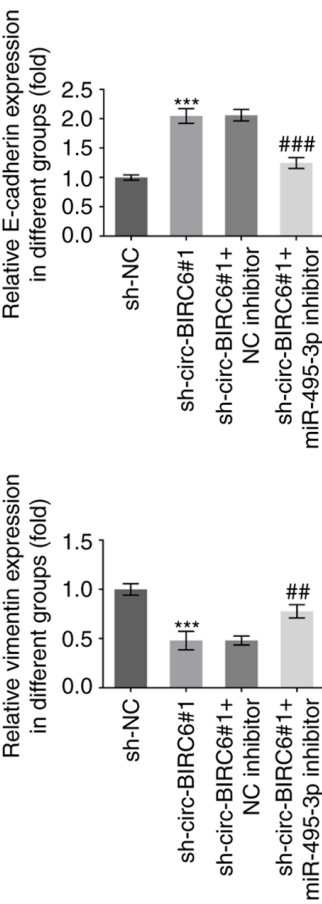
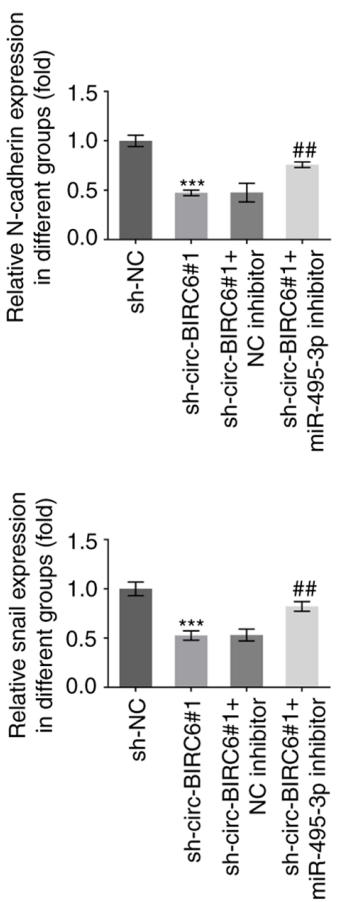

Figure 7. circ-BIRC6 silencing suppresses the growth of bladder cancer xenografts via regulating the miR-495-3p/XBP1 signaling axis. (A and B) Photographs of tumors. (C) Tumor weights. (D) Growth curves of T24 tumor volume. mRNA and protein expression of XBP1 in tumor tissues of nude mice were examined using (E) reverse transcription-quantitative PCR and (F) western blotting, respectively. (G) Ki-67 expression was evaluated using immunohistochemical staining. Magnification, x200. (H) Expression levels of epithelial-mesenchymal transition-related proteins, including E-cadherin, N-cadherin, vimentin and snail, were examined using western blotting. ${ }^{* * *} \mathrm{P}<0.001 \mathrm{vs}$. sh-NC; ${ }^{\# \#} \mathrm{P}<0.01$, ${ }^{\# \# "} \mathrm{P}<0.001$ vs. sh-circ-BIRC6\#1 + NC inhibitor. NC, negative control; sh, short hairpin RNA; circ-BIRC6, circular RNA baculoviral IAP repeat-containing 6; miR, microRNA; XBP1, X-box binding protein 1; snail, snail family transcriptional repressor 1 .

miR-495-3p expression was markedly downregulated in $\mathrm{BC}$ cell lines. Notably, transfection with the miR-495-3p inhibitor partially restored the inhibitory effects on $\mathrm{BC}$ progression caused by circ-BIRC6 knockdown in BC cells. 
Subsequently, the present study identified that XBP1 was a direct target of miR-495-3p. XBP1 is a key factor involved in endoplasmic reticulum stress. In general, XBP1 encodes two subtypes: XBP1s contains nuclear localization signals and transcriptional activation domains, while XBP1u contains nuclear rejection signals (38). XBP1s/u is an indicator of XBP1s activity, which, as an independent prognostic indicator, can be used to predict the overall survival of patients with myeloma (39). The loss of XBP1 was discovered to prevent glioma growth and promote cellular apoptosis (40). Furthermore, XBP1 was found to accelerate proliferation and invasion in human esophageal squamous cell carcinoma by upregulating the expression levels of MMP9 (41). Additionally, it was reported that XBP1 induced snail expression to promote the EMT and invasion of breast cancer cells (42). Emerging evidence supports the notion that elevated XBP1s/u is associated with a poor prognosis in patients with BC (43). In the current study, it was demonstrated that XBP1s/u expression was markedly upregulated in BC cell lines, and that XBP1 expression was regulated by the circ-BIRC6/miR-495-3p signaling axis. The xenograft results further verified the inhibitory effects of circ-BIRC6 knockdown on the growth and EMT of BC via interacting with miR-495-3p/XBP1.

In conclusion, to the best of our knowledge, the present study demonstrated for the first time that circ-BIRC6 was highly expressed in BC cells. Functionally, circ-BIRC6 knockdown inhibited the proliferation, invasion, migration and EMT of BC cells. Mechanistically, circ-BIRC6 knockdown suppressed $\mathrm{BC}$ progression in vitro and in vivo via a novel circ-BIRC6/miR-495-3p/XBP1 signaling regulatory network. These findings highlight a novel regulatory mechanism (circ-BIRC6/miR-495-3p/XBP1 signaling axis) in BC for researchers in this field to explore further, thereby identifying a new theoretical basis for targeted therapy. However, the lack of studies verifying the clinical value of circ-BIRC6 in clinical BC tissue samples and experiments showing any dose effect of circ-BIRC6 silencing (such as initial cell cycle arrest that would lead to inhibition of cell proliferation) as well as the usage of only one $\mathrm{BC}$ cell line to clarify the effects of the circ-BIRC6/miR-495-3p/XBP1 signaling axis in BC are potential limitations of the present research. Additionally, whether the overexpression of circ-BIRC6 would enhance the tumorigenesis of normal cells (SV-HUC-1) should also be further investigated. Therefore, comprehensive and in-depth analyses are required in the future to validate the findings of the current study.

\section{Acknowledgements}

Not applicable.

\section{Funding}

No funding was received.

\section{Availability of data and materials}

The datasets used and/or analyzed during the current study are available from the corresponding author on reasonable request.

\section{Authors' contributions}

LZ, BW and YZ searched the literature and designed and performed the experiments. LZ, KY and BL analyzed and interpreted the data and wrote the manuscript. BW revised the manuscript. LZ and BL confirm the authenticity of all the raw data. All authors read and approved the final manuscript.

\section{Ethics approval and consent to participate}

The study protocol was approved by the Ethics Committee of The Third Xiangya Hospital, Central South University (Changsha, China).

\section{Patient consent for publication}

Not applicable.

\section{Competing interests}

The authors declare that they have no competing interests.

\section{References}

1. Siegel RL, Miller KD and Jemal A: Cancer Statistics, 2017. CA Cancer J Clin 67: 7-30, 2017.

2. Antoni S, Ferlay J, Soerjomataram I, Znaor A, Jemal A and Bray F: Bladder cancer incidence and mortality: A global overview and recent trends. Eur Urol 71: 96-108, 2017.

3. Ploeg M, Aben KK and Kiemeney LA: The present and future burden of urinary bladder cancer in the world. World J Urol 27: 289-293, 2009.

4. Roupret M, Babjuk M, Comperat E, Zigeuner R, Sylvester RJ, Burger M, Cowan NC, Gontero P, Van Rhijn BWG, Mostafid AH, et al: European association of urology guidelines on upper urinary tract urothelial carcinoma: 2017 Update. Eur Urol 73: 111-122, 2018.

5. Burger M, Grossman HB, Droller M, Schmidbauer J, Hermann G, Drăgoescu O, Ray E, Fradet Y, Karl A, Burgués JP, et al: Photodynamic diagnosis of non-muscle-invasive bladder cancer with hexaminolevulinate cystoscopy: A meta-analysis of detection and recurrence based on raw data. Eur Urol 64: 846-854, 2013.

6. Chen M, Zhuang C, Liu Y, Li J, Dai F, Xia M, Zhan Y, Lin J, Chen Z, He A, et al: Tetracycline-inducible shRNA targeting antisense long non-coding RNA HIF1A-AS2 represses the malignant phenotypes of bladder cancer. Cancer Lett 376: 155-164, 2016.

7. Wilusz JE and Sharp PA: Molecular biology. A circuitous route to noncoding RNA. Science 340: 440-441, 2013.

8. Zhang W, Liu T, Li T and Zhao X: Hsa_circRNA_102002 facilitates metastasis of papillary thyroid cancer through regulating miR-488-3p/HAS2 axis. Cancer Gene Ther 28: 229-293, 2021.

9. Jia YJ, Liu M and Wang S: CircRNA hsa_circRNA_0001776 inhibits proliferation and promotes apoptosis in endometrial cancer via downregulating LRIG2 by sponging miR-182. Cancer Cell Int 20: 412, 2020.

10. Sun Z, Niu S, Xu F, Zhao W, Ma R and Chen M: CircAMOTL1 promotes tumorigenesis through miR-526b/SIK2 axis in cervical cancer. Front Cell Dev Biol 8: 568190, 2020.

11. Yan D, Dong W, He Q, Yang M, Huang L, Kong J, Qin H, Lin T and Huang J: Circular RNA circPICALM sponges miR-1265 to inhibit bladder cancer metastasis and influence FAK phosphorylation. EBioMedicine 48: 316-331, 2019.

12. Chen B, Wei W, Huang X, Xie X, Kong Y, Dai D, Yang L, Wang J, Tang $\mathrm{H}$ and Xie $\mathrm{X}$ : circEPSTI1 as a prognostic marker and mediator of triple-negative breast cancer progression. Theranostics 8: 4003-4015, 2018.

13. Yang G, Wang X, Liu B, Lu Z, Xu Z, Xiu P, Liu Z and Li J: circ-BIRC6, a circular RNA, promotes hepatocellular carcinoma progression by targeting the miR-3918/Bcl2 axis. Cell Cycle 18: 976-989, 2019. 
14. Luk IS, Shrestha R, Xue H, Wang Y, Zhang F, Lin D, Haegert A Wu R, Dong X, Collins CC, et al: BIRC6 targeting as potential therapy for advanced, enzalutamide-resistant prostate cancer. Clin Cancer Res 23: 1542-1551, 2017.

15. Tang W, Xue R, Weng S, Wu J, Fang Y, Wang Y, Ji L, Hu T, Liu T, Huang X, et al: BIRC6 promotes hepatocellular carcinogenesis: Interaction of BIRC6 with $\mathrm{p} 53$ facilitating p53 degradation. Int J Cancer 136: E475-E487, 2015.

16. Luk SU, Xue H, Cheng H, Lin D, Gout PW, Fazli L, Collins CC, Gleave ME and Wang Y: The BIRC6 gene as a novel target for therapy of prostate cancer: Dual targeting of inhibitors of apoptosis. Oncotarget 5: 6896-6908, 2014.

17. Dong X, Lin D, Low C, Vucic EA, English JC, Yee J, Murray N, Lam WL, Ling V, Lam S, et al: Elevated expression of BIRC6 protein in non-small-cell lung cancers is associated with cancer recurrence and chemoresistance. J Thorac Oncol 8: 161-170, 2013.

18. Livak KJ and Schmittgen TD: Analysis of relative gene expression data using real-time quantitative PCR and the 2(-Delta Delta C(T)) method. Methods 25: 402-408, 2001.

19. He Q, Zhao L, Liu Y, Liu X, Zheng J, Yu H, Cai H, Ma J, Liu L, Wang P, et al: circ-SHKBP1 regulates the angiogenesis of U87 glioma-exposed endothelial cells through miR-544a/FOXP1 and miR-379/FOXP2 pathways. Mol Ther Nucleic Acids 10: 331-348, 2018.

20. Zhang J, Liu H, Hou L, Wang G, Zhang R, Huang Y, Chen X and Zhu J: Circular RNA_LARP4 inhibits cell proliferation and invasion of gastric cancer by sponging miR-424-5p and regulating LATS1 expression. Mol Cancer 16: 151, 2017.

21. Bi J, Liu H, Dong W, Xie W, He Q, Cai Z, Huang J and Lin T: Circular RNA circ-ZKSCAN1 inhibits bladder cancer progression through miR-1178-3p/p21 axis and acts as a prognostic factor of recurrence. Mol Cancer 18: 133, 2019.

22. Li M, Liu Y, Liu J, Li W, Li N, Xue D, Zhang X and Wang P: Circ_0006332 promotes growth and progression of bladder cancer by modulating MYBL2 expression via miR-143. Aging (Albany NY) 11: 10626-10643, 2019.

23. Dai R, Jiang Q, Zhou Y, Lin R, Lin H, Zhang Y, Zhang J and Gao X: Lnc-STYK1-2 regulates bladder cancer cell proliferation migration, and invasion by targeting miR-146b-5p expression and AKT/STAT3/NF-kB signaling. Cancer Cell Int 21: 408, 2021.

24. He H, Yi L, Zhang B, Yan B, Xiao M, Ren J, Zi D, Zhu L, Zhong Z, Zhao X, et al: USP24-GSDMB complex promotes bladder cancer proliferation via activation of the STAT3 pathway. Int J Biol Sci 17: 2417-2429, 2021.

25. Abdollah F, Gandaglia G, Thuret R, Schmitges J, Tian Z, Jeldres C, Passoni NM, Briganti A, Shariat SF, Perrotte P, et al: Incidence, survival and mortality rates of stage-specific bladder cancer in United States: A trend analysis. Cancer Epidemiol 37: 219-225, 2013

26. Chen M, Li J, Zhuang C and Cai Z: Increased lncRNA ABHD11-AS1 represses the malignant phenotypes of bladder cancer. Oncotarget 8: 28176-28186, 2017.

27. Li Y, Wan B, Liu L, Zhou L and Zeng Q: Circular RNA circMTO1 suppresses bladder cancer metastasis by sponging miR-221 and inhibiting epithelial-to-mesenchymal transition. Biochem Biophys Res Commun 508: 991-996, 2019.

28. Georgakopoulos-Soares I, Chartoumpekis DV, Kyriazopoulou V and Zaravinos A: EMT factors and metabolic pathways in cancer. Front Oncol 10: 499, 2020.

29. Ko JH, Yang MH, Baek SH, Nam D, Jung SH and Ahn KS Theacrine attenuates epithelial mesenchymal transition in human breast cancer MDA-MB-231 cells. Phytother Res 33: 1934-1942, 2019.
30. Huang W, Lu Y, Wang F, Huang X and Yu Z: Circular RNA circRNA_103809 accelerates bladder cancer progression and enhances chemo-resistance by activation of miR-516a-5p/FBXL18 Axis. Cancer Manag Res 12: 7561-7568, 2020.

31. Fan C, Qu H, Xiong F, Tang Y, Tang T, Zhang L, Mo Y, Li X, Guo C, Zhang S, et al: CircARHGAP12 promotes nasopharyngeal carcinoma migration and invasion via ezrin-mediated cytoskeletal remodeling. Cancer Lett 496: 41-56, 2021.

32. Lin X, Huang C, Chen Z, Wang H and Zeng Y: CircRNA_100876 is upregulated in gastric cancer $(\mathrm{GC})$ and promotes the $\overline{\mathrm{GC}}$ cells' growth, migration and invasion via miR-665/YAP1 signaling. Front Genet 11: 546275, 2020.

33. Yang H, Zhao M, Zhao L, Li P, Duan Y and Li G: CircRNA BIRC6 promotes non-small cell lung cancer cell progression by sponging microRNA-145. Cell Oncol 43: 477-488, 2020.

34. Wang L and Liu J: Research progress of competing endogenous RNA. Sheng Wu Yi Xue Gong Cheng Xue Za Zhi 34: 967-971, 2017 (In Chinese).

35. Qian J, Garg A, Li F, Shen Q and Xiao K: lncRNA LUNAR1 accelerates colorectal cancer progression by targeting the miR-495-3p/MYCBP axis. Int J Oncol 57: 1157-1168, 2020.

36. Zhao G, Zhang L, Qian D, Sun Y and Liu W: miR-495-3p inhibits the cell proliferation, invasion and migration of osteosarcoma by targeting $\mathrm{C} 1 \mathrm{q} / \mathrm{TNF}-$ related protein 3 . OncoTargets Ther 12 : 6133-6143, 2019.

37. Mutalifu N, Du P, Zhang J, Akbar H, Yan B, Alimu S, Tong L and Luan X: Circ_0000215 Increases the Expression of CXCR2 and promoted the progression of glioma cells by sponging miR-495-3p. Technol Cancer Res Treat 19: 1533033820957026, 2020. doi:10.1177/1533033820957026.

38. Yoshida H, Oku M, Suzuki M and Mori K: pXBP1(U) encoded in XBP1 pre-mRNA negatively regulates unfolded protein response activator pXBP1(S) in mammalian ER stress response. J Cell Biol 172: 565-575, 2006.

39. Bagratuni T, Wu P, Gonzalez de Castro D, Davenport EL, Dickens NJ, Walker BA, Boyd K, Johnson DC, Gregory W, Morgan GJ and Davies FE: XBP1s levels are implicated in the biology and outcome of myeloma mediating different clinical outcomes to thalidomide-based treatments. Blood 116: 250-253, 2010.

40. Romero-Ramirez L, Cao H, Nelson D, Hammond E, Lee AH, Yoshida H, Mori K, Glimcher LH, Denko NC, Giaccia AJ, et al: $\mathrm{XBP} 1$ is essential for survival under hypoxic conditions and is required for tumor growth. Cancer Res 64: 5943-5947, 2004.

41. Xia T, Tong S, Fan K, Zhai W, Fang B, Wang SH and Wang JJ: XBP1 induces MMP-9 expression to promote proliferation and invasion in human esophageal squamous cell carcinoma. Am J Cancer Res 6: 2031-2040, 2016.

42. Li H, Chen X, Gao Y, Wu J, Zeng F and Song F: XBP1 induces snail expression to promote epithelial- to-mesenchymal transition and invasion of breast cancer cells. Cell Signal 27: 82-89, 2015.

43. Chen W, Zhou J, Wu K, Huang J, Ding Y, Yun EJ, Wang B, Ding C, Hernandez E, Santoyo J, et al: Targeting XBP1-mediated $\beta$-catenin expression associated with bladder cancer with newly synthetic oridonin analogues. Oncotarget 7: 56842-56854, 2016.

This work is licensed under a Creative Commons Attribution-NonCommercial-NoDerivatives 4.0 International (CC BY-NC-ND 4.0) License. 